\title{
Physical Distancing Measures and Walking Activity in Middle-aged and Older Residents in Changsha, China, During the COVID-19 Epidemic Period: Longitudinal Observational Study
}

Yilun Wang ${ }^{1}$, MD, PhD; Yuqing Zhang ${ }^{2,3}$, DSC; Kim Bennell ${ }^{4}$, PhD; Daniel Kenta White ${ }^{5}$, PT, SCD; Jie Wei ${ }^{2,3,6}$, $\mathrm{PhD}$; Ziying $\mathrm{Wu}^{1}$, MD; Hongyi $\mathrm{He}^{1}$, MD; Shaohui $\mathrm{Liu}^{6}$, MS; Xianghang Luo ${ }^{7,8}, \mathrm{MD}, \mathrm{PhD}$; Shuo Hu${ }^{8,9}, \mathrm{MD}, \mathrm{PhD}$; Chao Zeng ${ }^{1,2,3^{*}}, \mathrm{MD}, \mathrm{PhD}$; Guanghua Lei ${ }^{1,8,10^{*}}, \mathrm{MD}, \mathrm{PhD}$

\footnotetext{
${ }^{1}$ Department of Orthopaedics, Xiangya Hospital, Central South University, Changsha, China

${ }^{2}$ Division of Rheumatology, Allergy, and Immunology, Department of Medicine, Massachusetts General Hospital, Boston, MA, United States

${ }^{3}$ The Mongan Institute, Massachusetts General Hospital, Harvard Medical School, Boston, MA, United States

${ }^{4}$ Centre for Health, Exercise and Sports Medicine, The University of Melbourne, Melbourne, Australia

${ }^{5}$ Department of Physical Therapy, University of Delaware, Newark, DE, United States

${ }^{6}$ Health Management Center, Xiangya Hospital, Central South University, Changsha, China

${ }^{7}$ Department of Endocrinology, Endocrinology Research Center, Xiangya Hospital, Central South University, Changsha, China

${ }^{8}$ National Clinical Research Center of Geriatric Disorders, Xiangya Hospital, Central South University, Changsha, China

${ }^{9}$ Department of Nuclear Medicine, Xiangya Hospital, Central South University, Changsha, China

${ }^{10}$ Hunan Key Laboratory of Joint Degeneration and Injury, Changsha, China

*these authors contributed equally
}

Corresponding Author:

Guanghua Lei, MD, PhD

Department of Orthopaedics

Xiangya Hospital

Central South University

Xiangya Road 87

Changsha, 410008

China

Phone: 86073189753006

Email: lei guanghua@csu.edu.cn

\section{Abstract}

Background: Physical distancing measures taken to contain COVID-19 transmission may substantially reduce physical activity levels and cause individuals to adopt a more sedentary lifestyle.

Objective: The objective of this study is to determine if there was any change in daily steps, an important component of daily physical activity, and examine risk factors for frequent low daily steps during the COVID-19 epidemic.

Methods: We used data collected from the Step Study, a population-based longitudinal study of walking activity among residents aged $\geq 40$ years in Changsha, China. Daily steps were collected via a smartphone linked to WeChat, a social networking platform. We plotted mean daily steps and the prevalence of low daily steps ( $\leq 1500$ steps/day) 30 days before (reference period) and 30 days after (epidemic period) January 21, 2020 (date of the first COVID-19 case diagnosed in Changsha), and compared it with the same corresponding period from 2019. We examined the association of risk factors with the prevalence of frequent low daily steps ( $\leq 1500$ steps/day for $\geq 14$ days) using logistic regression.

Results: Among 3544 participants (mean age 51.6 years; $n=1226$ females, $34.6 \%$ ), mean daily steps dropped from 8097 to 5440 and the prevalence of low daily steps increased from $3 \%$ (2287/76,136 person-day) to $18.5 \%$ (12,951/70,183 person-day) during the reference and epidemic periods, respectively. No such phenomenon was observed during the corresponding period in 2019. Older age $(P$ for interaction=.001) and female sex $(P$ for interaction<.001) were both associated with a higher prevalence of frequent low daily steps and were more pronounced during the epidemic period. More education was associated with a lower prevalence of frequent low daily steps during the reference period but not the epidemic period $(P$ for interaction=.34). Body mass index or comorbidity were not associated with frequent low daily steps during either period. 
Conclusions: Daily steps of Changsha residents aged $\geq 40$ years dropped significantly during the COVID-19 period, especially among older adults and females. Although successful physical distancing, measured by the rapid downward trend in daily step counts of residents, played a critical role in the containment of the COVID-19 epidemic, our findings of an increase in the prevalence of frequent low daily steps raise concerns about unintended effects on physical activity.

(J Med Internet Res 2020;22(10):e21632) doi: 10.2196/21632

\section{KEYWORDS}

COVID-19; pandemic; physical distancing; steps; walking activity

\section{Introduction}

COVID-19 has caused morbidity and mortality worldwide [1]. To control this highly contagious infectious disease, many countries have implemented "physical distancing" and "shelter-in-place" measures to contain COVID-19 transmission $[2,3]$. However, such measures may substantially reduce physical activity levels and cause individuals to adopt a more sedentary lifestyle [4].

There is ample evidence that regular physical activity is crucial for health, with physical inactivity characterized as the fourth leading cause of global mortality [5]. Results from the National Health and Nutrition Examination Survey (NHANES) and the Women's Health Study both showed that a lower number of daily steps, which is an important component of daily physical activity, was significantly associated with higher all-cause mortality [6,7]. Studies also demonstrated that individuals who walked less than 1500 daily steps for 14 days were at a higher risk of muscle mass loss and low insulin sensitivity [8,9]. To date, several studies have reported changes in daily steps of residents in areas affected by COVID-19 [10-14]; however, none of these studies specifically described the prevalence of frequent low daily steps ( $\leq 1500$ steps/day for $\geq 14$ days over one month) $[8,9]$, a strong predictor of poor health outcomes, and examined its risk factors.

Using data collected from the Step Study, a longitudinal study conducted among the urban residents of Changsha, China, we therefore described the trends of daily steps around the COVID-19 epidemic period in 2020 and compared them with that of a similar period one year earlier. We examined the relationships between several sociodemographic factors, anthropometric factors, and comorbidity and the prevalence of frequent low daily steps.

\section{Methods}

\section{Study Population}

The Step Study (registration number: ChiCTR1800017977) is a population-based longitudinal study initiated in September 2018 in Changsha, China. The aims of the Step Study were to describe patterns of walking activity, factors related to walking activity, and its sequelae among the community-living population. Participants in the Step Study comprised individuals who had their annual physical checkup at Xiangya Hospital of Central South University in Changsha, China $[15,16]$. To be eligible for the Step Study, participants had to meet the following criteria: (1) be a resident of Changsha; (2) be aged $\geq 40$ years; (3) own a personal smartphone and have a WeChat account; and (4) be willing and able to give consent. Individuals with severe mental illness were ineligible. During each annual physical checkup, participants were queried about their sociodemographic and lifestyle factors, comorbidities, health-related symptoms and signs (eg, joint pain), and ability to perform daily activities. They also received clinical examinations and laboratory tests, including physical function tests (eg, lower limb muscle strength measurements).

For each participant, walking activity measured as daily step counts was collected through a smartphone linked to WeChat. WeChat is a multipurpose social network platform (Tencent Inc) with approximately 1.1 billion monthly active users in China [17]. One of its apps can extract daily step count information from the accelerometer sensor in a smartphone. Thus, if a participant is a WeChat user and wears a smartphone, his/her step counts can be captured by WeChat's app.

\section{Study Outcome}

The outcome variable was daily step counts recorded by the accelerometer sensor in the smartphone and extracted by WeChat. To be eligible for the current analysis of daily step counts, we required participants to wear their smartphone for $\geq 10$ hours on a given day, a standard convention for measuring daily walking $[18,19]$. The smartphone wear time was calculated as the difference between the times of the first recorded step count and the last recorded step count each day. This algorithm was used in the Activity Inequality Project to calculate daily step counts for more than 700,000 individuals across 111 countries [19]. Participants with no valid daily step count were excluded in the current analysis. We defined a low daily step count as $\leq 1500$ steps/day [8,9]. If a participant had $\geq 14$ days of low daily step counts over a 30-day period, we considered that person as having experienced frequent low daily steps [8,9].

We conducted two validation studies to assess the accuracy of daily step counts collected from WeChat. To determine the accuracy of steps measured at various walking speeds by iOS and Android devices, we visually counted steps from 14 subjects walking on a treadmill at $4.8,6.4,8.0$, and $9.6 \mathrm{~km} / \mathrm{h}$ while subjects held/wore smartphones in different positions (ie, pants pocket, hand, and arm). These methods are consistent with previous studies [20-22]. We found step count accuracy to be high, with intraclass correlation coefficients (ICCs) ranging from 0.64 to 0.99 . Second, we assessed the accuracy of step counts extracted from WeChat in free-living conditions. Specifically, 36 participants from the Step Study were instructed to wear both a Fitbit Charge 3 (Fitbit Inc), as the criterion measure [23], and their personal smartphone for 7 consecutive days [24]. The results also demonstrated a moderate to high 
agreement on step counts, with ICCs ranging from 0.67 to 0.81 . Detailed information from these validation studies is shown in Multimedia Appendix 1.

\section{Study Exposures}

Information on age, sex, educational level, height, weight, and comorbidity were obtained from the annual physical checkup visit. Body mass index was calculated. The modified Charlson Comorbidity Index (CCI) was computed based on self-reported comorbidities [25].

\section{Statistical Analyses}

On January 22, 2020, one day after the first case of COVID-19 was diagnosed in Changsha (January 21, 2020, ie, the index day) the municipal government issued an emergency notice to implement physical distancing measures (ie, staying at home, closing schools, working from home if possible, travelling only when necessary, and cancelling mass gatherings) [26,27]. In this analysis, we defined the time interval from January 22 to February 20, 2020 (30 days after the index date), as the COVID-19 epidemic period, and the time interval from December 22, 2019, to January 20, 2020 (30 days before the index date), as the reference period. Since the COVID-19 epidemic occurred around the holiday season of Chinese New Year, for the purpose of comparison we also used data collected between January 2 and March 3, 2019, which corresponded to the same Chinese lunar calendar period. Details of the selection of study periods are shown in Multimedia Appendix 2.

First, we plotted the mean daily steps from December 22, 2019, to February 20, 2020 (around COVID-19 epidemic period), and mean daily steps from January 2 to March 3, 2019 (historic comparison period), respectively, using a 3-day moving average smooth method [28]. Second, we used the same approach to plot the prevalence of low daily steps ( $\leq 1500$ steps/day) for the corresponding periods. We calculated the mean difference (MD) and its $95 \%$ confidence interval for daily steps using Generalized Estimating Equations (GEE) between the epidemic period and reference period in 2020, and the corresponding periods in 2019, respectively. Specifically, we included each qualified daily step count into the GEE model using the PROC GENMOD procedure in SAS (Version 9.4; SAS Institute) with identity links to calculate the MD and its $95 \%$ CI between the epidemic and reference periods. We added the REPEATED statement to account for correlation of the repeated measurements of individuals' daily step counts [29].

Similarly, prevalence ratios (PR) were calculated for the prevalence of low daily steps ( $\leq 1500$ steps/day) between the two comparative time periods in 2019 and 2020, respectively [30]. Finally, we estimated the prevalence of frequent low daily steps ( $\leq 1500$ steps/day for $\geq 14$ days over 30 days) during epidemic and reference periods and examined whether age, sex, BMI, educational level, and comorbidity were associated with the prevalence of frequent low daily steps using logistic regression. We tested the additive effect measure of modification of physical distancing with each of the risk factors mentioned above by adding an interaction term in the regression model [31].

All $P$ values for interaction were two-sided and $P$ for interaction $<.05$ was considered statistically significant for all tests. All statistical analyses were conducted using SAS (Version 9.4).

\section{Ethical Considerations}

This study was approved by the Ethics Committee of Xiangya Hospital, Central South University (\#201806910), and written informed consent was obtained from study participants.

\section{Results}

A total of 7262 Changsha residents aged $\geq 40$ years had a physical checkup at the study center between September 2018 and January 2020, and 4145 of them (57.1\%) had a WeChat account and agreed to participate in the Step Study. Of these, 3544 with at least one valid daily step count during the study period were included in the analysis (Table 1). The mean age of participants was 51.6 (SD 8.9) years, 1226 (34.6\%) participants were females, and the mean BMI of participants was 24.0 (SD 4.3) kg/m². Overall, $2616(73.8 \%)$ participants were Android users, 765 (21.6\%) were iOS users, and 163 $(4.6 \%)$ participants' phone types were unknown. 
Table 1. Baseline characteristics of included participants.

\begin{tabular}{|c|c|c|c|}
\hline Characteristics & Total sample $(\mathrm{N}=3544)$ & Males $(n=2318)$ & Females $(n=1226)$ \\
\hline Age (years), mean (SD) & $51.6(8.9)$ & $51.6(8.8)$ & $51.5(9.0)$ \\
\hline \multicolumn{4}{|l|}{ Age (years), n (\%) } \\
\hline $40-49$ & $1733(48.9)$ & $1117(48.2)$ & $616(50.2)$ \\
\hline $50-59$ & $1190(33.6)$ & $818(35.3)$ & $372(30.3)$ \\
\hline $60-70$ & $452(12.7)$ & $271(11.7)$ & $181(14.8)$ \\
\hline$\geq 70$ & $169(4.8)$ & $112(4.8)$ & $57(4.7)$ \\
\hline $\operatorname{BMI}\left(\mathrm{kg} / \mathrm{m}^{2}\right)$, mean $(\mathrm{SD})^{\mathrm{a}}$ & $24.0(4.3)$ & $24.8(4.2)$ & $22.5(4.3)$ \\
\hline \multicolumn{4}{|l|}{ BMI $\left(\mathrm{kg} / \mathrm{m}^{2}\right), \mathrm{n}(\%)^{\mathrm{b}}$} \\
\hline$<25$ & 1908 (59.6) & $1043(49.2)$ & $865(80.0)$ \\
\hline$\geq 25$ & $1294(40.4)$ & $1075(50.8)$ & $219(20.0)$ \\
\hline \multicolumn{4}{|l|}{ Education, $\mathbf{n}(\%)^{\mathbf{b}}$} \\
\hline High school or below & $564(22.1)$ & $328(19.7)$ & $236(26.5)$ \\
\hline Junior college & $621(24.3)$ & $372(22.4)$ & 249 (27.9) \\
\hline University or above & $1369(53.6)$ & $962(57.9)$ & $407(45.6)$ \\
\hline \multicolumn{4}{|c|}{ Charlson Comorbidity Index, n (\%) } \\
\hline 0 & $2759(77.8)$ & $1789(77.2)$ & $970(79.1)$ \\
\hline$\geq 1$ & $785(22.2)$ & $529(22.8)$ & $256(20.9)$ \\
\hline
\end{tabular}

${ }^{\mathrm{a}} \mathrm{N}=3202$.

${ }^{b} \mathrm{~N}=2554$.

As shown in Figure 1 and Table 2, daily steps (mean 8097 steps/day, range 6942-9153 steps/day) during the reference period (30 days prior to the COVID-19 epidemic in 2020) were similar to that during the corresponding period in 2019 (mean 7872 steps/day, range 6649-8912 steps/day). However, the daily steps decreased substantially after implementing physical distancing measures, from 8624 steps/day on the day before the index day to 4121 steps/day on Day 4 after the index day; this trend continued during the rest of the epidemic period. Compared with the reference period, the mean daily steps dropped by 2678 steps (95\% CI 2582-2763). However, this trend was not observed during the corresponding period in 2019. 
Figure 1. Average daily step count around the Chinese Lunar New Year period among participants in 2019 and 2020 . Day 0 represents the index date; in 2020, this represents the date of the first COVID-19 case diagnosed in Changsha.

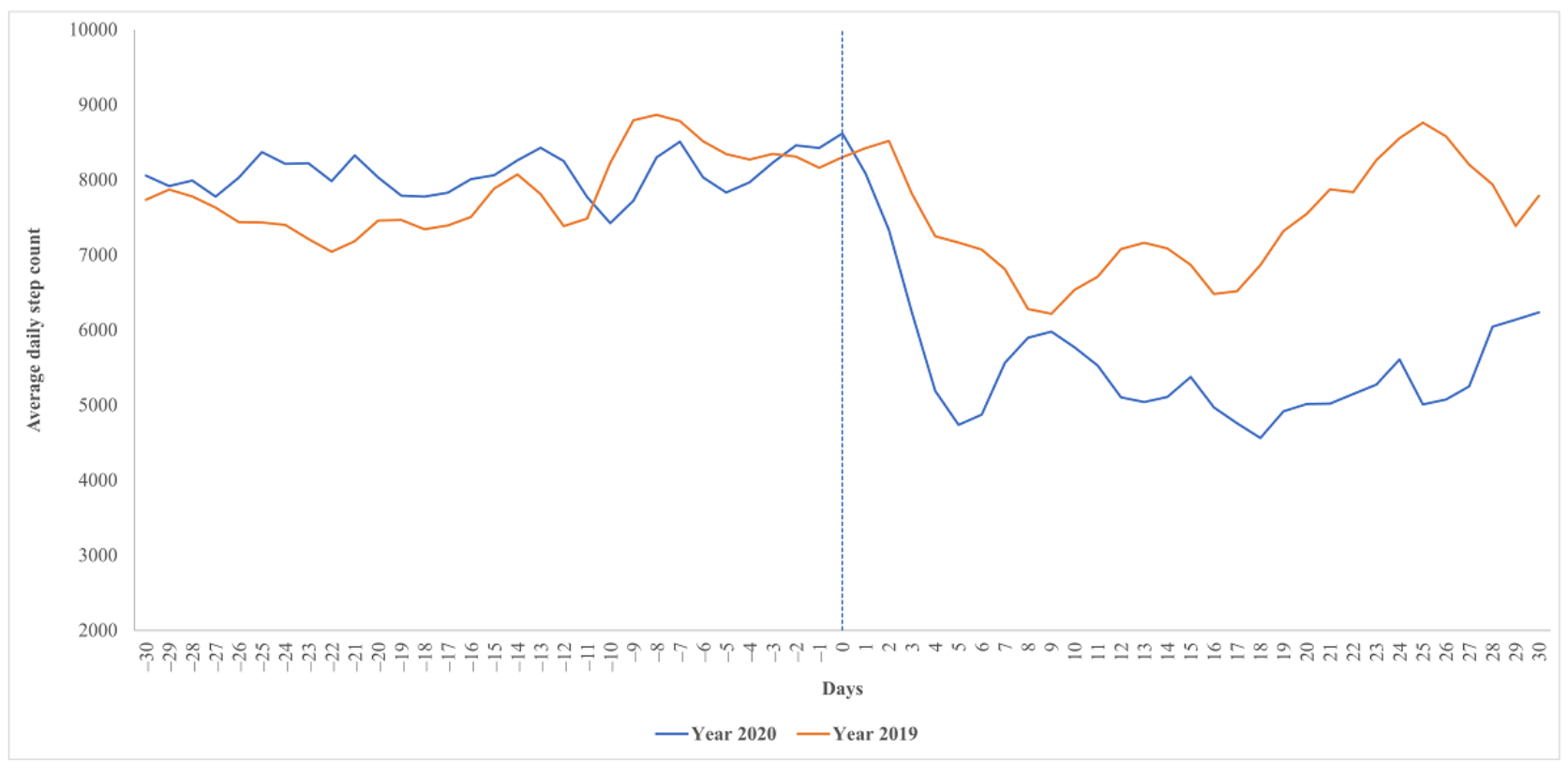

Table 2. Associations of time period with daily step count.

\begin{tabular}{|c|c|c|c|c|}
\hline \multirow[t]{2}{*}{ Time period } & \multicolumn{2}{|c|}{2019 daily step count } & \multicolumn{2}{|c|}{2020 daily step count } \\
\hline & Mean (SD) & Mean difference $(95 \% \mathrm{CI})^{\mathrm{a}}$ & Mean (SD) & Mean difference $(95 \% \mathrm{CI})^{\mathrm{a}}$ \\
\hline Reference & $7872(4842)$ & 0 (reference) & 8097 (4793) & 0 (reference) \\
\hline Epidemic & 7472 (4979) & $-413(-501$ to -325$)$ & $5440(4571)$ & $-2672(-2763$ to -2582$)$ \\
\hline
\end{tabular}

${ }^{\mathrm{a}}$ Mean differences were adjusted for age and sex.

Figure 2 and Table 3 present the prevalence of low daily steps ( $\leq 1500$ steps/day) in 2019 and 2020. The prevalence of low daily steps was similar during the reference period in 2020 (3.0\%, 2287/76,136 person-day) and the corresponding period in 2019 (3.3\%, 1006/30,647 person-day). In contrast, the prevalence of low daily steps increased substantially after implementing physical distancing measures, from $2.0 \%$
(53/2693) on the day prior to the index date to $25.5 \%$ (639/2505) on Day 4 after the index date; this trend continued during the rest of the follow-up period. Compared with the reference period, the PR of low daily steps was 6.2 (95\% CI 5.8-6.7). However, no such trend was observed during the entire historic comparison period in 2019. 
Figure 2. Prevalence of low daily step count ( $\leq 1500$ steps/day) around the Chinese Lunar New Year period among participants in 2019 and 2020 . Day 0 represents the index date; in 2020, this represents the date of the first COVID-19 case diagnosed in Changsha.

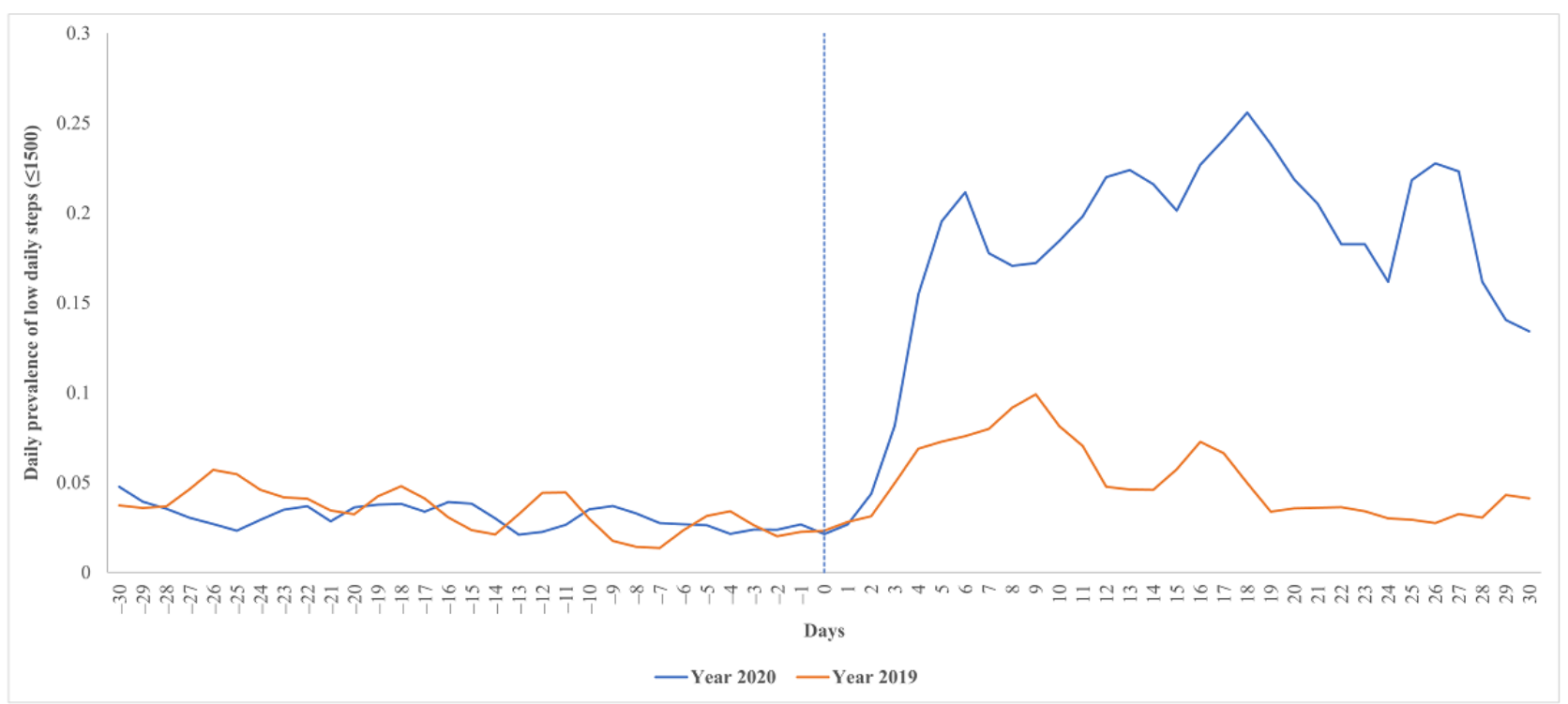

Table 3. Associations of time period with prevalence of low daily steps ( $\leq 1500$ steps/day).

\begin{tabular}{|c|c|c|c|c|}
\hline \multirow[t]{2}{*}{ Time period } & \multicolumn{2}{|l|}{2019 low daily steps } & \multicolumn{2}{|c|}{2020 low daily steps } \\
\hline & Person-day, n (\%) & Prevalence ratio $(95 \% \mathrm{CI})^{\mathrm{a}}$ & Person-day, n (\%) & Prevalence ratio $(95 \% \mathrm{CI})^{\mathrm{a}}$ \\
\hline Reference & $1006(3.3)$ & 1.0 (reference) & $2287(3.0)$ & 1.0 (reference) \\
\hline Epidemic & $1488(5.1)$ & $1.6(1.4-1.7)$ & $12,951(18.5)$ & $6.2(5.8-6.7)$ \\
\hline
\end{tabular}

${ }^{\mathrm{a}}$ Prevalence ratios were adjusted for age and sex.

As shown in Table 4, only $12(0.4 \%)$ of 2879 participants had walked less than $\leq 1500$ steps/day for 14 days or more (frequent low daily steps) during the 2020 reference period; however, the prevalence of frequent low daily steps increased to $7.4 \%$ (196/2655) during the COVID-19 epidemic period, after physical distancing measures were implemented. Older age $(P$ for interaction=.001) and female sex $(P$ for interaction<.001) were both associated with a higher prevalence of frequent low daily steps than their counterparts during the reference and COVID-19 epidemic periods, and such associations were more pronounced during the epidemic period. Participants with a university education or more had a lower prevalence of frequent low daily steps than those with only high school or less education during the reference period but this was not observed during the COVID-19 epidemic period. During the physical distancing period, no significant interaction between education and prevalence of frequent low daily steps was observed ( $P$ for interaction=.34). There was no apparent association of either BMI or CCI with the prevalence of frequent low daily steps during either period. 
Table 4. Association of prevalence of frequent low daily steps cases ( $\leq 1500$ steps/day for $\geq 14$ days) and basic characteristics.

\begin{tabular}{|c|c|c|c|c|c|c|c|}
\hline \multirow[t]{2}{*}{ Characteristics } & \multicolumn{3}{|c|}{ Reference period } & \multicolumn{3}{|c|}{ Epidemic period } & \multirow{2}{*}{$\begin{array}{l}P \text { values for } \\
\text { interaction }\end{array}$} \\
\hline & Participants, $\mathrm{n}$ & Cases, n (\%) & $\mathrm{PR}^{\mathrm{a}}(95 \% \mathrm{CI})^{\mathrm{b}}$ & Participants, $\mathrm{n}$ & Cases, n (\%) & PR $(95 \% \mathrm{CI})^{\mathrm{b}}$ & \\
\hline Total & 2879 & $12(0.4)$ & $\mathrm{N} / \mathrm{A}^{\mathrm{c}}$ & 2655 & $196(7.4)$ & N/A & N/A \\
\hline Age (years) & & & & & & & .001 \\
\hline $40-49$ & 1543 & $1(0.1)$ & $1.0(\mathrm{ref})^{\mathrm{d}}$ & 1470 & $84(5.7)$ & 1.0 (ref) & N/A \\
\hline $50-59$ & 957 & $8(0.8)$ & $9.9(1.2-0.0)$ & 871 & 69 (7.9) & $1.7(1.2-2.3)$ & N/A \\
\hline $60-70$ & 308 & $2(0.7)$ & $9.2(0.8-102.6)$ & 257 & $32(12.5)$ & $2.2(1.5-3.4)$ & N/A \\
\hline$\geq 70$ & 71 & $1(1.4)$ & $21.0(1.3-331.8)$ & 57 & $11(19.3)$ & $3.0(1.6-5.7)$ & N/A \\
\hline Sex & & & & & & & $<.001$ \\
\hline Males & 1904 & $7(0.4)$ & 1.0 (ref) & 1793 & $75(4.2)$ & 1.0 (ref) & N/A \\
\hline Females & 975 & $5(0.5)$ & $2.2(0.6-7.9)$ & 862 & $121(14.0)$ & $3.4(2.5-4.6)$ & N/A \\
\hline Body mass index & & & & & & & .250 \\
\hline$<25$ & 1557 & $7(0.5)$ & 1.0 (ref) & 1415 & $109(7.7)$ & 1.0 (ref) & N/A \\
\hline$\geq 25$ & 1006 & $3(0.3)$ & $0.8(0.2-3.2)$ & 269 & $61(6.2)$ & $1.2(0.9-1.7)$ & N/A \\
\hline Education & & & & & & & .335 \\
\hline $\begin{array}{l}\text { High school or be- } \\
\text { low }\end{array}$ & 441 & $6(1.4)$ & 1.0 (ref) & 389 & 45 (11.6) & 1.0 (ref) & N/A \\
\hline Junior college & 522 & $2(0.4)$ & $0.3(0.1-1.7)$ & 460 & $31(6.7)$ & $0.7(0.4-1.0)$ & N/A \\
\hline University or above & 1228 & $2(0.2)$ & $0.2(0.0-1.1)$ & 1134 & $90(7.9)$ & $1.0(0.7-1.4)$ & N/A \\
\hline Charlson Comorbidity & ndex & & & & & & .345 \\
\hline 0 & 2294 & $9(0.4)$ & 1.0 (ref) & 2115 & $150(7.1)$ & 1.0 (ref) & N/A \\
\hline$\geq 1$ & 585 & $3(0.5)$ & $0.9(0.2-3.8)$ & 540 & $46(8.5)$ & $1.1(0.7-1.5)$ & N/A \\
\hline
\end{tabular}

${ }^{\mathrm{a}} \mathrm{PR}$ : prevalence ratio.

${ }^{\mathrm{b}}$ Prevalence ratios were adjusted for age and sex.

${ }^{\mathrm{c}} \mathrm{N} / \mathrm{A}$ : not applicable.

${ }^{\mathrm{d}}$ Ref: reference.

\section{Discussion}

\section{Principal Findings}

Using objective data collected from the longitudinal Step Study, we found that daily steps among middle-aged and older residents in Changsha dropped rapidly and substantially (2672 fewer daily steps on average) after implementing physical distancing measures during the COVID-19 epidemic period. In addition, more than $7 \%(196 / 2655)$ of residents had walked $\leq 1500$ steps/day for $\geq 14$ days over the one-month epidemic period compared with $0.4 \%(12 / 2879)$ of residents in the month prior to the epidemic. The reduction of steps/day during the COVID-19 epidemic was more pronounced among older adults and females.

\section{Comparison With Previous Studies}

To date, several studies have reported changes in daily steps during the COVID-19 epidemic [10-14]. One worldwide study based on a smartphone app (Argus) showed that mean daily steps in different regions decreased by $5.5 \%$ and $27.3 \%$ (287 and 1432 steps/day, respectively) within 10 and 30 days after the COVID-19 pandemic was declared [10]. Another study that used a wristwatch with an embedded accelerometer (Withings) demonstrated a marked decrease in daily steps (from $25 \%$ to $54 \%$ ) following the official dates of home confinement in countries adopting a total lockdown [11]. Similar findings were also reported in other countries [12-14]. Our results demonstrated that such a change also occurred in the Chinese population. Furthermore, we examined daily steps within the same period in the previous year and observed no such change during this period, which enabled us to minimize the potential impact of the holiday season of Chinese New Year on daily steps.

In addition, we found that the effect of implementation of physical distancing measures on frequent low daily steps was more pronounced among older adults and females. Previous studies have examined associations between walking activities and sociodemographic factors, anthropometric factors, and comorbidity. The results from the NHANES report indicated that those of advancing age (OR 1.95, per 16.7-year increments) and female sex (OR 1.86) both had higher odds of walking less than 5000 steps/day [32]. Another study found that education was associated with increased walking activity, with one additional year of education associated with a 560 daily steps 
increase [33]. Our results corroborate these findings. However, after the implementation of physical distancing measures, the prevalence of frequent low daily steps among residents with university or above education was similar to those with high school or below education, suggesting both groups followed physical distancing measures and reduced their outdoor walking activities. Nevertheless, the magnitude of relative increase in the prevalence of frequent low daily steps during the COVID-19 epidemic appeared to be greater among residents with university or above education than among those with high school or below education, indicating the former are more likely to follow instructions and communicate effectively with health providers [33,34]. Previous studies also showed that both BMI and comorbidities (eg, hypertension and diabetes) were associated with fewer daily steps $[6,7,35,36]$, but this was not the case in the present study, nor was any association modified by the implementation of physical distancing measures.

\section{Public Health Implications}

Physical distancing measures play a critical role in containing COVID-19 transmission and monitoring population mobility data can provide evidence as to whether people are complying with these measures [37]; however, the impact of physical distancing on other aspects of daily life should not be overlooked. Recently, Hall and colleagues [4] commented that "The world is experiencing an extraordinary, life-altering challenge due to the COVID-19 pandemic. Many countries have become accustomed to a new normal - 'social distancing' and 'shelter-in-place' are now a part of everyday vernacular and life." The authors warned that this health crisis has the potential to further impact and accelerate the pandemic of physical inactivity and sedentary behavior.

Our data showed that average daily steps among residents of Changsha dropped by more than $30 \%$ (from 8097 to 5440) during the COVID-19 epidemic period after implementation of physical distancing measures. These data raise concerns about the potential adverse effects of such measures on health and well-being. Previous studies have showed that higher daily steps are associated with better cardiometabolic profiles and lower all-cause mortality $[6,7,38]$. Other studies have also found that a decrease in daily steps of 2000 steps, irrespective of previous habitual step counts, increases the risk of insulin sensitivity and higher cardiovascular events $[39,40]$. Thus, our findings have important implications for public health recommendations and the prevention of other health crises during the COVID-19 pandemic. Furthermore, our data showed that the reduction in daily steps is much more common among older adults and females. In general, older adults and females are more likely to develop sedentary behaviors, placing them at greater risk of various diseases related to inactivity $[32,41]$; thus, the worsening trend of physical inactivity during the COVID-19 epidemic period compounds the risk of sequelae related to a sedentary lifestyle.

It is uncertain as to how long it will take to completely control the COVID-19 pandemic worldwide. If similar trends toward a sedentary lifestyle are seen in other countries, the avoidance of further sedentary lifestyle behaviors and promotion of regular physical activity during this time are an urgent global public health issue. It is also unknown whether the observed decline in daily walking is a temporary phenomenon that may revert back to baseline levels after the disease is under control; thus, further longitudinal studies are needed so that evidence-based strategies can be developed and implemented to encourage greater participation in regular physical activity.

\section{Strengths and Limitations}

Several strengths of our study are noteworthy. First, we used data from a large population-based longitudinal study (Step Study), which allowed not only investigation of COVID-19-related changes in daily step counts from over 3500 residents, but also inclusion of a historic comparison period from the prior year to account for a secular trend in daily step counts. Second, the study took advantage of a social network platform (WeChat) to capture daily step count data via smartphone in real time among the community-living population. As a smartphone has become a daily necessity for most adults, this approach allowed long-term monitoring of daily step count trends. This contrasts to previous studies using wearable devices (accelerometers) that generally only collect step count data for a relatively short time (eg, a week or less) [42]. It can be challenging to extrapolate such short-term data to describe step count patterns over a long period owing to various potential confounders [42].

Potential limitations of our study also deserve comment. First, the WeChat app may underestimate daily step counts because some individuals may not always carry their smartphone with them [43], especially when participants were housebound. Thus, some light walking activities at home may not be captured. However, one previous study reported that the average wear time of smartphones among Chinese citizens was more than 13 hours during the day time, indicating that most walking activities should be captured by a smartphone [19]. Second, although our validation study demonstrated that daily step counts collected from iOS and Android devices both showed close agreement with actual step counts under controlled laboratory settings, previous studies found that iOS and Android devices have different accuracies in capturing the daily step count under free-living conditions [44]. This could have led to misclassification of daily step counts in this study. Third, participants in our study were slightly younger (51.6 versus 54.8 years) and more likely to be male (65.4\% versus $51.2 \%)$ than those who are aged $\geq 40$ years and live in Changsha, according to the latest census data in 2010. However, our results showed that the prevalence of frequent low daily steps increased more among women and older people, suggesting that the overall prevalence of frequent low steps among all residents in Changsha aged $\geq 40$ years may be even higher than what was reported in our study. Fourth, participants in our study were urban residents in Changsha who came to Xiangya Hospital for their annual health checkup. The percentage of WeChat users among these individuals $(57.1 \%)$ was higher than that of the population with the same age range in China (41.5\%) [45]. Thus, our findings may not be generalizable to residents living in other parts of China, especially those living in rural areas. Finally, we were unable to capture the intensity of steps (eg, slow versus fast steps); however, total steps/day has recently been shown 
to be an important predictor of mortality independent of step intensity [6].

\section{Conclusions}

Using data collected from a large population-based longitudinal study, we demonstrated that walking activity, indicated by daily step count, decreased rapidly and substantially during the COVID-19 epidemic period among middle-aged and older adult
Chinese residents living in urban areas. These results suggest that appropriate strategies need to be taken to encourage residents to actively engage in regular physical activity while maintaining personal hygiene and physical distancing. They also call for further studies to evaluate whether the low levels of walking activity observed following the implementation physical distancing measures will be maintained and whether they will have significant adverse impacts on health outcomes.

\section{Acknowledgments}

This work was supported by the National Natural Science Foundation of China $(81772413,81702207,81702206,81930071)$, the National Health and Medical Research Council Principal Research Fellowship, the National Key Research and Development Project (2018YFB1105705), and the Key Research and Development Program of Hunan Province (2018SK2070, 2018SK2071). No funding bodies had any role in the study design, data collection and analysis, decision to publish, or preparation of the manuscript.

The authors thank Xiaoxiao Li, Wei Li, Huizhong Long, Jiatian Li, Haochen Wang, Yuqing Wang, Ning Wang, Bei Xu, Zidan Yang, Jing Wu, Zhenglei Zhu, and Xin Huang (Xiangya Hospital) for their contribution to this study.

\section{Authors' Contributions}

GL and CZ had full access to all of the data in the study and take responsibility for the integrity of the data and the accuracy of the data analysis. CZ and GL are joint corresponding authors. All authors have read the manuscript, provided critical feedback on intellectual content, and approved the final manuscript. CZ, GL, YW, and YZ contributed to the concept and design. All authors contibuted to the acquisition, analysis, or interpretation of data. YW, CZ, GL, and YZ drafted the manuscript. All authors critically revised the manuscript for important intellectual content. YZ and JW contributed to statistical analysis. CZ, GL, and JW obtained funding. YW, CZ, and GL provided administrative, technical, or material support. GL, YZ, and CZ provided supervision.

\section{Conflicts of Interest}

None declared.

\section{Multimedia Appendix 1}

Validation study.

[DOCX File, 55 KB-Multimedia Appendix 1]

\section{Multimedia Appendix 2}

Diagram of the study periods. Chinese New Year fell on January 25 in 2020 and February 5 in 2019.

[PNG File, 234 KB-Multimedia Appendix 2]

\section{References}

1. Coronavirus disease (COVID-19) Pandemic. World Health Organization. URL: https://www.who.int/emergencies/diseases/ novel-coronavirus-2019 [accessed 2020-03-30]

2. Merriam-Webster. Social Distancing. 2020. URL: https://www.merriam-webster.com/dictionary/social\%20distancing [accessed 2020-03-30]

3. Miller K. Here's what a shelter in place order means during the coronavirus pandemic. Prevention. URL: https://www. prevention.com/health/amp31738348/shelter-in-place-ordercoronavirus/ [accessed 2020-03-30]

4. Hall G, Laddu DR, Phillips SA, Lavie CJ, Arena R. A tale of two pandemics: How will COVID-19 and global trends in physical inactivity and sedentary behavior affect one another? Prog Cardiovasc Dis 2020 Apr 08:1 [FREE Full text] [doi: 10.1016/j.pcad.2020.04.005] [Medline: 32277997]

5. Global Health Risks: Mortality and Burden of Disease Attributable to Selected Major Risks. World Health Organization. URL: http://apps.who.int/iris/bitstream/10665/44203/1/9789241563871 eng.pdf [accessed 2020-04-05]

6. Saint-Maurice PF, Troiano RP, Bassett DR, Graubard BI, Carlson SA, Shiroma EJ, et al. Association of Daily Step Count and Step Intensity With Mortality Among US Adults. JAMA 2020 Mar 24;323(12):1151-1160. [doi: 10.1001/jama.2020.1382] [Medline: 32207799]

7. Lee I, Shiroma EJ, Kamada M, Bassett DR, Matthews CE, Buring JE. Association of Step Volume and Intensity With All-Cause Mortality in Older Women. JAMA Intern Med 2019 May 29:1 [FREE Full text] [doi: 10.1001/jamainternmed.2019.0899] [Medline: $\underline{\text { 31141585] }}$ 
8. Breen L, Stokes KA, Churchward-Venne TA, Moore DR, Baker SK, Smith K, et al. Two weeks of reduced activity decreases leg lean mass and induces "anabolic resistance" of myofibrillar protein synthesis in healthy elderly. J Clin Endocrinol Metab 2013 Jun;98(6):2604-2612. [doi: 10.1210/jc.2013-1502] [Medline: 23589526]

9. Knudsen SH, Hansen LS, Pedersen M, Dejgaard T, Hansen J, Hall GV, et al. Changes in insulin sensitivity precede changes in body composition during 14 days of step reduction combined with overfeeding in healthy young men. J Appl Physiol (1985) 2012 Jul;113(1):7-15. [doi: 10.1152/japplphysiol.00189.2011] [Medline: 22556394]

10. Tison GH, Avram R, Kuhar P, Abreau S, Marcus GM, Pletcher MJ, et al. Worldwide Effect of COVID-19 on Physical Activity: A Descriptive Study. Annals of Internal Medicine 2020 Jun 29:29. [doi: 10.7326/m20-2665]

11. Pépin JL, Bruno RM, Yang R, Vercamer V, Jouhaud P, Escourrou P, et al. Wearable Activity Trackers for Monitoring Adherence to Home Confinement During the COVID-19 Pandemic Worldwide: Data Aggregation and Analysis. J Med Internet Res 2020 Jun 19;22(6):e19787 [FREE Full text] [doi: 10.2196/19787] [Medline: 32501803]

12. Di Sebastiano KM, Chulak-Bozzer T, Vanderloo LM, Faulkner G. Don't Walk So Close to Me: Physical Distancing and Adult Physical Activity in Canada. Front Psychol 2020;11:1895 [FREE Full text] [doi: 10.3389/fpsyg.2020.01895] [Medline: $\underline{32849110]}$

13. Sun S, Folarin AA, Ranjan Y, Rashid Z, Conde P, Stewart C, RADAR-CNS Consortium. Using Smartphones and Wearable Devices to Monitor Behavioral Changes During COVID-19. J Med Internet Res 2020 Sep 25;22(9):e19992 [FREE Full text] [doi: 10.2196/19992] [Medline: $\underline{32877352}$ ]

14. Vetrovsky T, Frybova T, Gant I, Semerad M, Cimler R, Bunc V, et al. The detrimental effect of COVID-19 nationwide quarantine on accelerometer-assessed physical activity of heart failure patients. ESC Heart Fail 2020 Jul 22:1 [FREE Full text] [doi: 10.1002/ehf2.12916] [Medline: $\underline{\text { 32696600] }}$

15. Zeng C, Wei J, Terkeltaub R, Yang T, Choi HK, Wang Y, et al. Dose-response relationship between lower serum magnesium level and higher prevalence of knee chondrocalcinosis. Arthritis Res Ther 2017 Oct 24;19(1):236 [FREE Full text] [doi: 10.1186/s13075-017-1450-6] [Medline: 29065924]

16. Zeng C, Wei J, Li H, Yang T, Zhang F, Pan D, et al. Relationship between Serum Magnesium Concentration and Radiographic Knee Osteoarthritis. J Rheumatol 2015 Jul;42(7):1231-1236. [doi: 10.3899/jrheum.141414] [Medline: 26034158]

17. The number of WeChat users reached 1.1 billion in 2019. SOHU. URL: https://www.sohu.com/a/362122894 513553 [accessed 2020-03-30]

18. Tudor-Locke C, Camhi SM, Troiano RP. A catalog of rules, variables, and definitions applied to accelerometer data in the National Health and Nutrition Examination Survey, 2003-2006. Prev Chronic Dis 2012;9:E113 [FREE Full text] [doi: 10.5888/pcd9.110332] [Medline: 22698174]

19. Althoff T, Sosič R, Hicks JL, King AC, Delp SL, Leskovec J. Large-scale physical activity data reveal worldwide activity inequality. Nature 2017 Dec 20;547(7663):336-339 [FREE Full text] [doi: 10.1038/nature23018] [Medline: 28693034]

20. Höchsmann C, Knaier R, Eymann J, Hintermann J, Infanger D, Schmidt-Trucksäss A. Validity of activity trackers, smartphones, and phone applications to measure steps in various walking conditions. Scand J Med Sci Sports 2018 Jul;28(7):1818-1827. [doi: 10.1111/sms.13074] [Medline: 29460319]

21. Hekler EB, Buman MP, Grieco L, Rosenberger M, Winter SJ, Haskell W, et al. Validation of Physical Activity Tracking via Android Smartphones Compared to ActiGraph Accelerometer: Laboratory-Based and Free-Living Validation Studies. JMIR mHealth uHealth 2015 Apr 15;3(2):e36 [FREE Full text] [doi: 10.2196/mhealth.3505] [Medline: 25881662]

22. Case MA, Burwick HA, Volpp KG, Patel MS. Accuracy of smartphone applications and wearable devices for tracking physical activity data. JAMA 2015 Feb 10;313(6):625-626. [doi: 10.1001/jama.2014.17841] [Medline: 25668268]

23. Straiton N, Alharbi M, Bauman A, Neubeck L, Gullick J, Bhindi R, et al. The validity and reliability of consumer-grade activity trackers in older, community-dwelling adults: A systematic review. Maturitas 2018 Jun;112:85-93. [doi: 10.1016/j.maturitas.2018.03.016] [Medline: 29704922]

24. Spence JC, Burgess J, Rodgers W, Murray T. Effect of pretesting on intentions and behaviour: a pedometer and walking intervention. Psychol Health 2009 Sep;24(7):777-789. [doi: 10.1080/08870440801989938] [Medline: 20205026]

25. Katz JN, Chang LC, Sangha O, Fossel AH, Bates DW. Can comorbidity be measured by questionnaire rather than medical record review? Med Care 1996 Jan;34(1):73-84. [doi: 10.1097/00005650-199601000-00006] [Medline: $\underline{8551813]}$

26. Key points of prevention and control of COVID-2019 by Center for Disease Control and Prevention in Changsha city. Changsha Government. URL: http://www.changsha.gov.cn/jdhy/hygq/hygq/202001/t20200122_6403516.html [accessed 2020-03-15]

27. Take epidemic prevention and control as the top priority during COVID-2019 in Changsha city. Changsha Gpvernment. URL: http://www.changsha.gov.cn/szf/ywdt/zwdt/202001/t20200122_6403423.html [accessed 2020-03-15]

28. Harmsen SM, Chang YH, Hattrup SJ. Simple Moving Average: A Method of Reporting Evolving Complication Rates. Orthopedics 2016 Sep 01;39(5):e869-e876. [doi: 10.3928/01477447-20160517-02] [Medline: 27220115]

29. Orelien J. Model Fitting in PROC GENMOD. SAS. URL: https://support.sas.com/resources/papers/proceedings/proceedings/ sugi26/p264-26.pdf [accessed 2020-10-21]

30. Spiegelman D, Hertzmark E. Easy SAS calculations for risk or prevalence ratios and differences. Am J Epidemiol 2005 Aug 01;162(3):199-200. [doi: 10.1093/aje/kwi188] [Medline: 15987728] 
31. Rothman K. Chapter 11, Measuring Interaction. In: Epidemiology, An Introduction. New York: Oxford University Press; 2012.

32. Sisson SB, Camhi SM, Tudor-Locke C, Johnson WD, Katzmarzyk PT. Characteristics of step-defined physical activity categories in U.S. adults. Am J Health Promot 2012 Jan;26(3):152-159. [doi: 10.4278/ajhp.100326-QUAN-95] [Medline: 22208412]

33. Kari JT, Viinikainen J, Böckerman P, Tammelin TH, Pitkänen N, Lehtimäki T, et al. Education leads to a more physically active lifestyle: Evidence based on Mendelian randomization. Scand J Med Sci Sports 2020 Jul;30(7):1194-1204. [doi: 10.1111/sms.13653] [Medline: 32176397]

34. Goldman DP, Smith JP. Can patient self-management help explain the SES health gradient? Proc Natl Acad Sci U S A 2002 Aug 06;99(16):10929-10934. [doi: 10.1073/pnas.162086599] [Medline: 12140364]

35. Sumner J, Uijtdewilligen L, Yee ACH, Xian SNH, Barreira TV, Sloan RA, et al. Volume and Intensity of Stepping Activity and Cardiometabolic Risk Factors in a Multi-ethnic Asian Population. Int J Environ Res Public Health 2020 Jan 30;17(3):E863 [FREE Full text] [doi: 10.3390/ijerph17030863] [Medline: 32019086]

36. Schuna JM, Brouillette RM, Foil HC, Fontenot SL, Keller JN, Tudor-Locke C. Steps per day, peak cadence, body mass index, and age in community-dwelling older adults. Med Sci Sports Exerc 2013 May;45(5):914-919. [doi: 10.1249/MSS.0b013e31827e47ac] [Medline: 23247705]

37. Buckee CO, Balsari S, Chan J, Crosas M, Dominici F, Gasser U, et al. Aggregated mobility data could help fight COVID-19. Science 2020 Apr 10;368(6487):145-146. [doi: 10.1126/science.abb8021] [Medline: 32205458]

38. Hajna S, Ross NA, Dasgupta K. Steps, moderate-to-vigorous physical activity, and cardiometabolic profiles. Prev Med 2018 Feb;107:69-74 [FREE Full text] [doi: 10.1016/j.ypmed.2017.11.007] [Medline: 29126915]

39. Dwyer T, Ponsonby A, Ukoumunne OC, Pezic A, Venn A, Dunstan D, et al. Association of change in daily step count over five years with insulin sensitivity and adiposity: population based cohort study. BMJ 2011 Jan 13;342(jan13 1):c7249-c7249. [doi: 10.1136/bmj.c7249] [Medline: 21233153]

40. Yates T, Haffner SM, Schulte PJ, Thomas L, Huffman KM, Bales CW, et al. Association between change in daily ambulatory activity and cardiovascular events in people with impaired glucose tolerance (NAVIGATOR trial): a cohort analysis. Lancet 2014 Mar 22;383(9922):1059-1066. [doi: 10.1016/S0140-6736(13)62061-9] [Medline: 24361242]

41. Varona-Pérez P, Pérez-Jiménez D, Alfonso-Sagué K, García-Pérez RM, Bonet-Gorbea M, Fernández-González J. Patterns of Physical Activity and Associated Factors in Cubans Aged 15-69 Years. MEDICC Rev 2016 Oct;18(4):20-25. [Medline: 27829650]

42. Shephard RJ, Park H, Park S, Aoyagi Y. Objective Longitudinal Measures of Physical Activity and Bone Health in Older Japanese: the Nakanojo Study. J Am Geriatr Soc 2017 Apr;65(4):800-807. [doi: 10.1111/jgs.14553] [Medline: 27943243]

43. Duncan MJ, Wunderlich K, Zhao Y, Faulkner G. Walk this way: validity evidence of iphone health application step count in laboratory and free-living conditions. J Sports Sci 2018 Aug;36(15):1695-1704. [doi: 10.1080/02640414.2017.1409855] [Medline: 29179653]

44. Fuller D, Colwell E, Low J, Orychock K, Tobin MA, Simango B, et al. Reliability and Validity of Commercially Available Wearable Devices for Measuring Steps, Energy Expenditure, and Heart Rate: Systematic Review. JMIR mHealth uHealth 2020 Sep 08;8(9):e18694 [FREE Full text] [doi: 10.2196/18694] [Medline: 32897239]

45. The 46th China Statistical Report on Internet Development. CNNIC. URL: https://www.cnnic.net.cn/hlwfzyj/hlwxzbg/ hlwtjbg/202009/t20200929 71257.htm [accessed 2020-09-30]

\section{Abbreviations}

CCI: Charlson Comorbidity Index

GEE: Generalized Estimating Equations

ICC: intraclass correlation coefficients

MD: mean difference

NHANES: National Health and Nutrition Examination Survey

PR: prevalence ratio 
Edited by G Eysenbach; submitted 19.06.20; peer-reviewed by M Alharbi, H Sasai; comments to author 12.09.20; revised version received 01.10.20; accepted 02.10.20; published 26.10 .20

Please cite as:

Wang Y, Zhang Y, Bennell K, White DK, Wei J, Wu Z, He H, Liu S, Luo X, Hu S, Zeng C, Lei G

Physical Distancing Measures and Walking Activity in Middle-aged and Older Residents in Changsha, China, During the COVID-19

Epidemic Period: Longitudinal Observational Study

J Med Internet Res 2020;22(10):e21632

URL: http://www.jmir.org/2020/10/e21632/

doi: $\underline{10.2196 / 21632}$

PMID: $\underline{33027035}$

(C) Yilun Wang, Yuqing Zhang, Kim Bennell, Daniel Kenta White, Jie Wei, Ziying Wu, Hongyi He, Shaohui Liu, Xianghang Luo, Shuo Hu, Chao Zeng, Guanghua Lei. Originally published in the Journal of Medical Internet Research (http://www.jmir.org), 26.10.2020. This is an open-access article distributed under the terms of the Creative Commons Attribution License (https://creativecommons.org/licenses/by/4.0/), which permits unrestricted use, distribution, and reproduction in any medium, provided the original work, first published in the Journal of Medical Internet Research, is properly cited. The complete bibliographic information, a link to the original publication on http://www.jmir.org/, as well as this copyright and license information must be included. 